Acta Crystallographica Section F

Structural Biology

and Crystallization

Communications

ISSN 1744-3091

\section{addenda and errata}

\title{
Crystallization and preliminary X-ray structural studies of human prouroguanylin. Corrigendum
}

\section{Len Ito, ${ }^{a}$ Yuji Hidaka, ${ }^{b} *$ Masaki Okumura, ${ }^{a}$ Hironori Konishi, ${ }^{b}$ Knut Adermann ${ }^{c}$ and Hiroshi Yamaguchi ${ }^{a *}$}

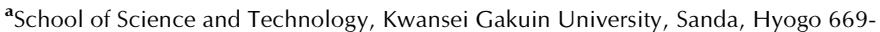
1337, Japan, ${ }^{\mathbf{b}}$ School of Science and Engineering, Kinki University, Higashi-Osaka, Osaka 577-8502, Japan, and ' IPF PharmaCeuticals GmbH, Feodor-Lynen-Strasse 31, D-30625 Hannover, Germany

Correspondence e-mail: yuji@life.kindai.ac.jp, hiroshi@kwansei.ac.jp

A correction is made to the list of authors for Ito et al. [Acta Cryst. (2008). F64, 531-532].

In the article by Ito et al. (2008) one of the authors names was not listed. The correct list of authors is Len Ito, Yuji Hidaka, Masaki Okumura, Hironori Konishi, Knut Adermann and Hiroshi Yamaguchi, as given above.

\section{References}

Ito, L., Hidaka, Y., Okumura, M., Konishi, H. \& Yamaguchi, H. (2008). Acta Cryst. F64, 531-532. 